\title{
REDUCING THE OPERATING COSTS OF AN APARTMENT BUILDING
}

\author{
Ján TAKÁCS ${ }^{*}$, Lukáš RÁCZ1
}

\begin{abstract}
Circulation pumps are mechanical devices, which are used to create the overpressure required for the transportation of a heat-transfer medium in heating technology as well as in other related technologies. In a circulation pump the mechanical energy generated by the drive machine - an electric motor is transformed to hydraulic energy, which consists of kinetic and static energy. In the pipeline of a heating system circulation pumps represent a source of hydraulic energy (positive differential pressure), which is consumed to transport the heat-transfer medium. During the flow, the heat-transfer medium puts up resistance to the so-called passive resistors, which consist of pressure losses from friction in the pipes and pressure losses due to local resistance.In this article the authors analyze the effect of a circulation pump on the operating costs in an apartment building. Different types of circulating pumps, ranging from the most unfavorable to the optimal, were selected.
\end{abstract}

Address

1 Slovak University of Technology in Bratislava Faculty of Civil Engineering, Department of Building Services, Radlinského 11, 81005 Bratislava, Slovakia

* Corresponding author: jan.takacs@stuba.sk

\section{Key words}

- Circulation pump,

- energy efficiency,

- energy saving.

\section{INTRODUCTION}

Circulation pumps are used in heating technology to create the overpressure required to overcome the hydraulic resistance of a heating network from the heat source, through the pipeline system, to the last heating element or apartment circuit. The most widespread heat-transfer medium is water (hot water up to $110{ }^{\circ} \mathrm{C}$ ). Heating systems or individual circuits require the pumps to generate lowto-medium pressure at relatively large mass flow rates. Centrifugal hydrodynamic pumps with electric motors are the best choices in order to fulfill these requirements. In smaller heating systems socalled inline pumps are built into the pipeline. The performance requirements and pump characteristics are very different and vary depending on the characteristics of the heating system. There are different types of pumps used in technical practice, which differ in their designs and hydraulic and material solutions.

\section{MAIN PARAMETERS AND BASIC TERMS OF PUMPING TECHNOLOGY}

The main pump parameters, which determines the size of the connecting throats, are the

mass flow rate $M_{h}(k g / h)$, operating pressure $\Delta p_{\check{c}}(k P a)$, specific energy $\mathrm{Y}(\mathrm{J} / \mathrm{kg})$, and transportation head $\mathrm{H}$ ( $\mathrm{m}$ v.s).

- The pump mass flow rate $M_{h}$ is defined as the quantity of fluid which is transported by the pump from the suction side to the outlet side at a certain time unit indicated in $\mathrm{kg} / \mathrm{s}, \mathrm{kg} / \mathrm{h}$. In terms of the pump's operation, it is necessary to define the volumetric flow rate at which the pump has the best rate of efficiency. This flow is a basic calculation parameter of the pump along with the speed $n_{a}$, depending on the power of the unit and the properties of the heat-transfer medium: the specific density $\rho$ and viscosity $\mu$. The mass flow rate of the heating system is given by: 


$$
\mathrm{M}_{\mathrm{h}}=\frac{Q}{\theta_{p}-\theta_{v}} \cdot 0.86(\mathrm{~kg} / \mathrm{h})
$$

where :

$\mathrm{Q}$ is the heat output, which the heating system has to supply in (W),

$\theta_{\mathrm{p}}$ - the temperature of the heat-transfer medium in the flow-in pipe in $\left({ }^{\circ} \mathrm{C}\right)$,

$\theta_{v}$ - the temperature of the heat-transfer medium in the return pipe in $\left({ }^{\circ} \mathrm{C}\right)$,

0.86 - is the constant gear

- The operating pressure $\Delta \mathrm{p}_{\mathrm{p}}(\mathrm{Pa}$ or $\mathrm{kPa})$ is an indicator which reflects the amount of the energy handed over to a unit of weight of the heat-transfer substance. In older scientific literature, the transportation head $\mathrm{H}$ (m water column) was used, which was enforced by the pump manufacturers. The relationship between $\mathrm{H}$ and $\Delta \mathrm{p}_{\mathrm{p}}$ is $1 \mathrm{~m}$ (water column) $=10 \mathrm{kPa}$. Pump manufacturers give either the operating pressure $\Delta p_{p}$ or the transportation head $\mathrm{H}$. The resulting pump working pressure is calculated as:

$$
\Delta \mathrm{p}_{\mathrm{p}}=\Delta \mathrm{p}_{\mathrm{fr} .}+\Delta \mathrm{p}_{\mathrm{jo}}+\Delta \mathrm{p}_{\mathrm{RA}}=\Sigma(\mathrm{R} . \mathrm{l})+\Sigma(\mathrm{Z})+\Delta \mathrm{p}_{\mathrm{RA}}(\mathrm{Pa})
$$

where :

$\Delta p_{p}$ is the operating pressure of the pump (Pa),

$\Delta \mathrm{p}_{\mathrm{p}}$ - the pressure drop by unit of resistance $(\mathrm{Pa})$,

$\Delta \mathrm{pf}_{\mathrm{r}}$ - the pressure drop by friction in the pipe (Pa),

$\Delta \mathrm{p}_{\mathrm{RA}}$ - the pressure drop of the regulation fittings $(\mathrm{Pa})$,

$\mathrm{Z}=\Delta \mathrm{p}_{\mathrm{j} . \text { odp }}$ - the pressure drop from the resistance embedded in the pipeline $(\mathrm{Pa})$,

$\mathrm{R}$ - the differential pressure $(\mathrm{Pa} / \mathrm{m})$,

1 - the length of the pipe section (m).

- The physically correct qualitative indicator of the pump is the specific energy $Y(\mathrm{~J} / \mathrm{kg})$, which is defined as the energy transferred by the pump per unit of the weight of the heattransfer medium. It is equal to the difference between the input and the output of the specific energy. The nominal specific energy $\mathrm{Y}_{\mathrm{a}}$ is bonded to the nominal mass flow rate and nominal speed $n_{n}$.

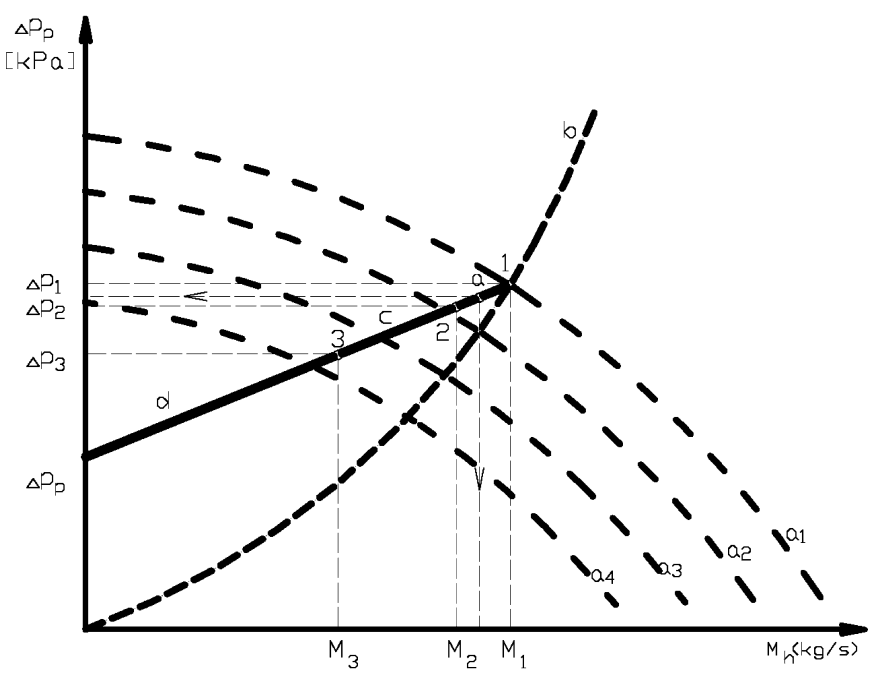

Fig. 1 Working characteristics of a pump and pipeline distribution network a-pump with a gradual change of speed (1-5), $b$-characteristics of heating system, $c$ - pump with constant pressure, $d$-pump with a proportional pressure, 1, 2 and $3-$ operating points.
The working characteristics of the pump represent the variations of the main parameters of the pump, the mass flow rate $\mathrm{M}_{\mathrm{h}}(\mathrm{kg} / \mathrm{h})$, or the volume flow $\mathrm{V}_{\mathrm{h}}\left(\mathrm{m}^{3} / \mathrm{h}\right)$, from the operating pressure $\Delta \mathrm{p}_{\mathrm{p}}(\mathrm{kPa})$ or the specific energy of the pump $\mathrm{Y}(\mathrm{J} / \mathrm{kg})$. Different characteristics of the pumps and piping network are shown in Fig. 1. At the intersection of both characteristics the working point of the pump and piping network can be found. At point 1, the pump delivers a mass flow rate $M_{1}$ at operating pressure $\Delta p_{1}$. By reducing the pump mass flow rate $\mathrm{M}_{2}$ (for example, by closing highly resistive valves with thermostatic valves) and increasing the operating pressure of the pump $\Delta \mathrm{p}_{1}$, it then changes the characteristics of the pipeline network and stabilizes the operation point 2 , respectively 3 . As a consequence, the flow rate and the differential pressure will increase across the connecting points.

\section{COMPARISON OF SOME CIRCULATING PUMPS}

Circulation pump 50 NTR-80 was originally installed in the apartment building. This pump was embedded in the pipeline. The original condition before the thermal insulation was a mass flow $\mathrm{M}_{\mathrm{h}, 1}$ $=0.69 \mathrm{dm}^{3} / \mathrm{s}$; and after the thermal insulation, the mass flow was $\mathrm{M}_{\mathrm{h}, 2}=$ $1.4 \mathrm{dm}^{3} / \mathrm{s}$. The operational pressures, as seen in Fig. 2, were originally $\mathrm{Y}_{1}=65 \mathrm{~J} / \mathrm{kg}$; after the thermal insulation, they were $\mathrm{Y}_{2}=65 \mathrm{~J} / \mathrm{kg}$. We have compared other circulating pumps to the 50 NTR-80-10 circulating pump.

From the second figure we can see that the pump embedded in the piping network was not suitable after the apartment building was thermally insulated. The original mass flow was decreased so that the pump is operating outside the recommended area. This causes it to operate unreliably and results in problems with balancing the system.

When designing a new pump, we considered the following pumps:

- Pump $\mathrm{N}^{\circ}$.1. with UPS 40-50 $250 \mathrm{~F}$ steady speed type, for mass flow

$\mathrm{M}_{\mathrm{h}, 1}=0.69 \mathrm{dm}^{3} / \mathrm{s}=2.5 \mathrm{~m}^{3} / \mathrm{h}$, and $\mathrm{H}=2.05 \mathrm{~m}$.

- Pump $\mathrm{N}^{\circ} .2$ with constant pressure type MAGNA 40-100 F, for mass flow $\mathrm{M}_{\mathrm{h}, 1}=0.69 \mathrm{dm}^{3} / \mathrm{s}=2.5 \mathrm{~m}^{3} / \mathrm{h}$, and $\mathrm{H}=2.05 \mathrm{~m}$.

- Pump $\mathrm{N}^{\circ} .3$ with proportional pressure type ALPFA 32-60, for mass flow $\mathrm{M}_{\mathrm{h}, 1}=0.69 \mathrm{dm}^{3} / \mathrm{s}=2.5 \mathrm{~m}^{3} / \mathrm{h}$, and $\mathrm{H}=2.05 \mathrm{~m}$.

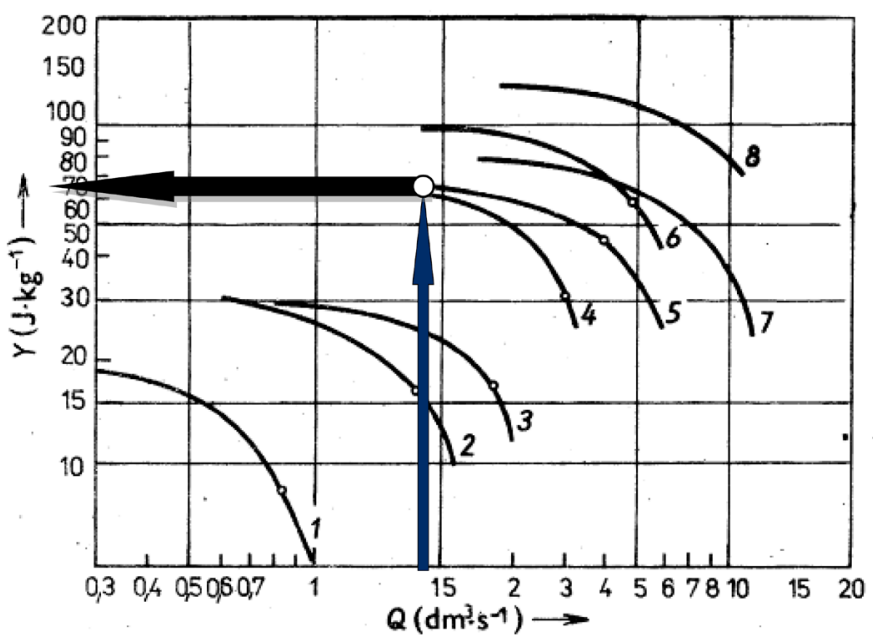

Fig. 2 Working characteristics of the 50 NTR-80-10 pump. 

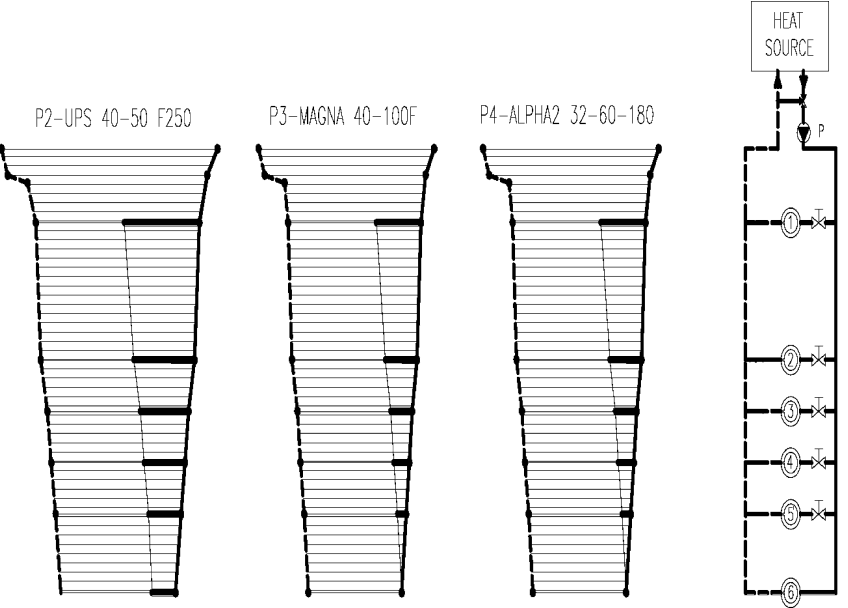

The course of the pressure diagram for the original heating system is shown in the diagram. $\mathrm{N}^{\circ} .3$

Fig. 3 Pressure diagram of the heating system with different pumps.

From Fig. 3 it is clear that pumps $\mathrm{P} 3$ and $\mathrm{P} 4$ have nearly the same pressure diagrams. Only the pressure diagram in pump $\mathrm{N}^{\circ} .2$ shows higher throttling on the lines into different branches. As an illustration, an inappropriate solution is graphically shown in Fig. 4. The original pump with high pressure is not suitable, because the higher pressure should be throttled on the control valve. This pressure is causing noise, which reduces the lifetime of the control valves and has large energy demands. This figure describes why it is important to replace outdated circulation pumps with steady progressive ones with new frequency converters.

\section{ECONOMIC EVALUATION OF THE MONITORED PUMPS}

We used a program for dimensioning circulating pumps called "WinCAPS". We calculated the investments and operating costs for the circulating pumps we designed in this program for the city of Bratislava and the length of the heating period $d=202$ days. The values are recorded in Table 1.
Price of $1 \mathrm{kWh}$ of electricity was obtained from the operator of the heat source in the apartment building.

The operating costs for the 50 NTR-80-10 pump were determined for two modes:

1 Continuous operation:

$\mathrm{PN}_{1}=\mathrm{d} . \mathrm{P} . \mathrm{T} . \varepsilon=202 \cdot 0.36 \cdot 24 \cdot 1.0=\underline{1745.3 \mathrm{kWh} / \mathrm{y}}$

2 Intermittent operation:

$\mathrm{PN}_{2}=\mathrm{d} . \mathrm{P} . \mathrm{T} . \varepsilon=202 \cdot 0.36 .24 .0 .63=\underline{1099.5 \mathrm{kWh} / \mathrm{y}}$

where :

d - days (-)

$\mathrm{T}-$ time $(\mathrm{h})$

$\mathrm{P}-$ power $(\mathrm{kW})$

$\varepsilon-$ coefficient of load $(-)$

Tab. 1 Investments and operating costs $(\epsilon)$ for various pumps.

\begin{tabular}{|c|c|c|c|c|c|c|}
\hline \multirow{2}{*}{ Order.N ${ }^{\circ}}$. & \multirow{2}{*}{ Type of pump } & IC & OC & E & $\sum$ ON & Total \\
\cline { 3 - 7 } & & $(€)$ & $(\mathrm{kWh} / \mathrm{r})$ & $(€ / \mathrm{kWh})$ & $(€ / \mathrm{r})$ & 237.184 \\
\hline 1 & 50 -NTR-80-10 & 421.4 & 1745.3 & 0.1359 & 658.602 \\
\hline 2 & 50 -NTR-80-10 & 421.4 & 1099.5 & 0.1359 & 149.426 & 570.844 \\
\hline 3 & UPS-40-50 F250 & 393.1 & 347.0 & 0.1359 & 47.157 & 440.257 \\
\hline 4 & MAGNA 40-100F & 685.4 & 80.0 & 0.1359 & 10.872 & 696.272 \\
\hline 5 & ALPHA2 32-60 180 & 281.3 & 66.0 & 0.1359 & 8.969 & 290.269 \\
\hline
\end{tabular}

Tab. 2 The return on investment $(\epsilon)$ in exchanging the original for the new UPS-40-50F250 pump.

\begin{tabular}{|c|c|c|c|c|c|c|c|}
\hline & 1 year & 2 years & 3 years & 4 years & 5 years & 6 years & 7 years \\
\hline 50 NTR-80-10 & 249.0 & 523.0 & 784.5 & 1046.0 & 1307.5 & 1569.0 & 1830.5 \\
\hline UPS-40-50 F250 & 442.6 & 492.1 & 541.6 & 591.2 & 640.7 & 690.2 & 739.7 \\
\hline difference & -193.6 & 30.9 & 242.8 & 454.8 & 666.8 & 878.8 & 1090.8 \\
\hline
\end{tabular}




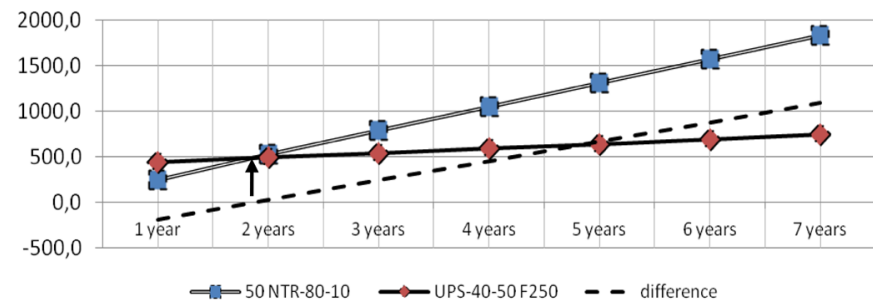

Fig. 5 The return on the investment.

The return on the investment for the replacement of the original 50 NTR-80-10 pump with full-time operations for the UPS 40-50 F250 pump is in Tab. 2.

From the graph (Fig. 5) it is obvious that the return on the investment will be in $2(1.8)$ years, taking into account an inflation rate of $5 \%$.

The return on investment for the replacement of the original 50 NTR-80-10 pump with a full-time operation for the MAGNA 40$100 \mathrm{~F}$ is in Tab. 3.

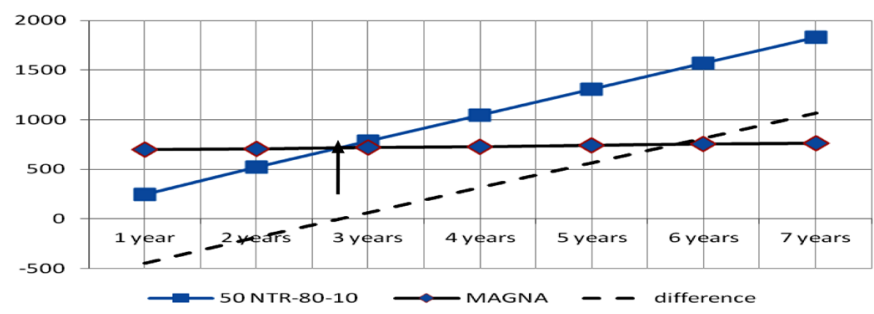

Fig. 6 The return on the investment.

From the graph (Fig. 6) it is obvious that the return on investment is in 3 (2.8) years, taking into account an inflation rate of 5\%.

The return on investment for the replacement of the original 50 NTR-80-10 pump with the full-time operation of the ALPHA2 32-60 180 is in Tab. 4.

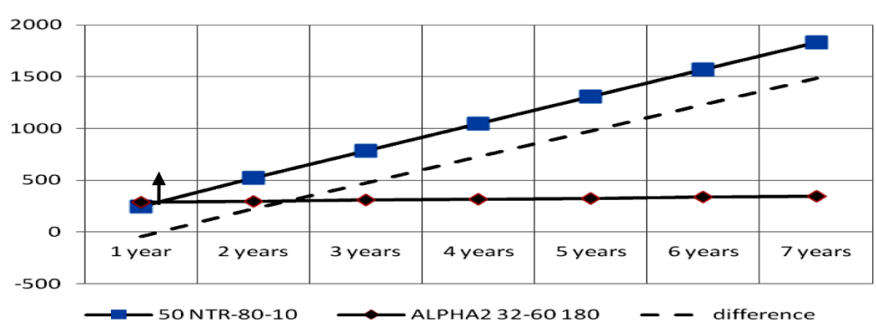

Fig. 7 The return on the investment.

From the graph (Fig. 7) it is obvious that the return on investment is in $1(0.8)$ years, taking into account an inflation rate of $5 \%$.

If we consider the intermittent operation of the original circulation pump (with the present 0.66), it would increase the return time for the UPS 40-50 F250 to 3.6 years, for the Magna 40-100F to 4.6 years, and the ALPHA2 32-60180 pump to 1.6 years.

A comparison of the investment and operating costs for the replacement of the pump is shown in Table. 5

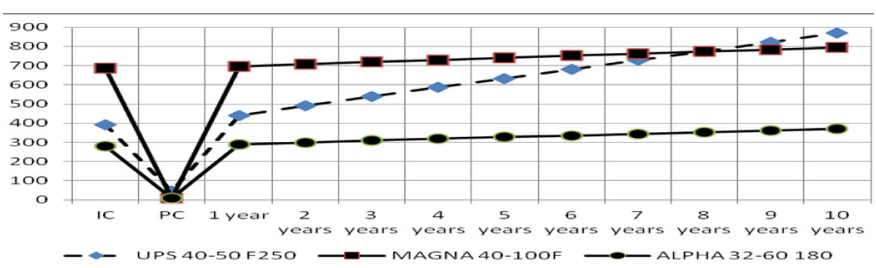

Fig. 8 The amount of the investment.

Where: P1 - UPS-40-50 F250, P2 - MAGNA 40-100F, P3 ALPHA2 32-60 180

From the graph (Fig.8) it is obvious that the P2 pump demands a lot of capital and is followed by P1 and P3. From an operational perspective, the most demanding pump is $\mathrm{P} 1$, followed by $\mathrm{P} 2$ and

Tab. 3 The return on investment $(\epsilon)$ in exchanging the original pump for the new MAGNA40-100F pump.

\begin{tabular}{|c|c|c|c|c|c|c|c|}
\hline & 1 year & 2 years & 3 years & 4 years & 5 years & 6 years & 7 years \\
\hline 50 NTR-80-10 & 249.0 & 523.0 & 784.5 & 1046.0 & 1307.5 & 1569.0 & 1830.5 \\
\hline MAGNA & 696.8 & 708.2 & 719.6 & 731.1 & 742.5 & 753.9 & 765.3 \\
\hline difference & -447.8 & -185.2 & 64.8 & 314.9 & 565.0 & 815.1 & 1065.2 \\
\hline
\end{tabular}

Tab. 4 The return on investment $(\epsilon)$ in exchanging the original pump for the new ALPHA2 32-60 180 pump.

\begin{tabular}{|c|c|c|c|c|c|c|c|}
\hline & 1 year & 2 years & 3 years & 4 years & 5 years & 6 years & 7 years \\
\hline 50 NTR-80-10 & 249.0 & 523.0 & 784.5 & 1046.0 & 1307.5 & 1569.0 & 1830.5 \\
\hline ALPHA2 32-60 180 & 290.7 & 300.1 & 309.6 & 319.0 & 328.4 & 337.8 & 347.2 \\
\hline difference & -41.7 & 222.9 & 474.9 & 727.0 & 979.1 & 1231.2 & 1483.2 \\
\hline
\end{tabular}

Tab. 5 Investments and operation costs $(\epsilon)$ for the replacement of the pumps.

\begin{tabular}{|c|c|c|c|c|c|c|c|c|c|c|c|c|}
\hline & IC & $\mathrm{PC}$ & 1 year & 2 years & 3 years & 4 years & 5 years & 6 years & 7 years & 8 years & 9 years & 10 years \\
\hline $\mathrm{P} 1$ & 393.1 & 47.2 & 49.51 & 99.03 & 148.54 & 198.06 & 247.57 & 297.09 & 346.60 & 396.12 & 445.63 & 495.15 \\
\hline Č2 P2 & 685.4 & 10.9 & 11.41 & 22.83 & 34.24 & 45.66 & 57.07 & 68.49 & 79.90 & 91.32 & 102.74 & 114.15 \\
\hline С̆3 Č2 P3 & 281.3 & 9.0 & 9.41 & 18.83 & 28.25 & 37.67 & 47.08 & 56.50 & 65.92 & 75.33 & 84.76 & 94.17 \\
\hline
\end{tabular}


P3. The best for our heating system is pump P3, which has the lowest operating costs.

\section{CONCLUSION}

A complex housing renovation leads to a substantial reduction in energy needs for the heating and preparation of domestic hot water. The original equipment of the heating system should be replaced by new, progressive and economically viable elements; we have in mind a new heating system with new pipelines, control valves and heating elements, as well as with sources of active pressure created by progressive circulation pumps with very low power consumption. By using new progressive circulation pumps with a continuous regulation of the speed to maintain static or proportional pressure, we can expect significant savings in the energy required for the operation of the circulation pump. The most significant savings are achieved by changing the speed with frequency converters, which are built into modern progressive pumps. This was confirmed by the analysis of the suitability of the circulation pumps and their operating costs.

\section{REFERENCES}

Brož, K. (1986) Heat supply, ČVUT, Prague.

Kadrnožka, J. - Ochrana, L. (2001) Heating. CERM, Brno.

Lulkovičová, O. et al. (2004) Sources of heat and small heat sources. Jaga, Bratislava.

Petráš, D. - Lulkovičová, O. - Takács, J. - Bašta, J. - Kabele, K. (2005) Heating in Family Houses and Apartment Buildings. Jaga, Bratislava, $231 \mathrm{pp}$.
Dahlsveen, T. - Petráš, D. - Hiř̌, J. (2003) Energy audit of buildings. Jaga group. Bratislava.

Épületgépészet 2000 (2001) Fütestechnika. Épuletgépészet kiadó kft., Budapest.

Rácz L. (2011) Diploma thesis - The design of a heat source and heating system for an apartment building and courtyard in Bratislava. Faculty of Civil Engineering, Department of Building Services, Bratislava, Slovakia. 